\title{
Publication of Research Presented at STFM and NAPCRG Conferences
}

Robert E. Post, MD, MS

Arch G. Mainous III, PbD ${ }^{2}$

Kendal E. O'Hare, $M D^{1}$

Dana E. King, MD, $M S^{2}$

Mario S. Maffei, $M D^{1}$

'Virtua Family Medicine Residency, Voorhees, New Jersey

${ }^{2}$ Department of Family Medicine, Medical University of South Carolina, Charleston, South Carolina
Conflicts of interest: authors report none.

\section{CORRESPONDING AUTHOR}

Robert E. Post, MD, MS

2225 Evesham Road, Suite 101

Voorhees, NJ 08043

rpost@virtua.org

\begin{abstract}
PURPOSE Presentations of research are important in the dissemination of new knowledge, but they do not reach the same audience as research published in journals. The purpose of this study was to evaluate the proportion of presentations at recent major primary care research conferences that have become published.
\end{abstract}

METHODS Oral and poster presentations for completed and work-in-progress projects from the 2007 and 2008 North American Primary Care Research Group (NAPCRG) and Society of Teachers of Family Medicine (STFM) annual conferences were included in the analysis. The first presenter for each presentation was searched on PubMed, and titles and abstracts for presentations were compared for content to titles and abstracts of potential matches found on PubMed. We analyzed the proportion of presentations that were published in peer-reviewed journals, mean time to publication, and the proportions of the type of journal in which the article appeared (family medicine vs other) were analyzed.

RESULTS There were 1,329 presentations included in the study. Overall, $34.4 \%$ of projects presented were also published. More oral presentations (42.9\%) were published than were poster presentations $(25.3 \%)(P<.001)$. Mean time to publication was 15.4 months. Oral presentations were published more quickly (13.7 months) than poster presentations (18.6 months) $(P<.001)$. Published reports appeared in 192 different journals. Family medicine journals accounted for $36.5 \%$ of published.

CONCLUSIONS More than one-third of all presentations at STFM and NAPCRG conferences were published in journals indexed in PubMed. Time to publication was comparable to that of other specialties. Fewer than 2 of every 5 reports were published are in a family medicine journal, suggesting vast breadth in family medicine research. Family medicine academicians need to refocus efforts on transforming presentations into published articles in peer-reviewed journals for broader dissemination of research findings.

Ann Fam Med 2013;11:258-261. doi:10.1370/afm.1503.

\section{INTRODUCTION}

$\mathrm{O}$ ral and poster presentations of original research are a key strategy in the dissemination of new knowledge in academic medicine. Unfortunately, these mechanisms have some significant limitations. First, the number of people who are exposed to the information presented at a professional meeting is relatively small, and they must rely on their memory when trying to implement the information or convey it to others. Furthermore, many professional meetings rely on a limited peer review of abstracts rather than complete manuscripts. Manuscripts published in peer-reviewed journals overcome these limitations by having (1) widespread dissemination, (2) a written document that can be used for years, and (3) more rigorous peer review. Consequently, to move our knowledge base forward, it is important that presentations of original research transition to peer-reviewed manuscripts submitted for publication.

That presentations at professional meetings do not transition to peerreviewed manuscripts is a problem faced by many medical specialties, ${ }^{1.5}$ 
though family medicine has had a variety of initiatives to increase research productivity over the past 25 years. ${ }^{6-9}$ An analysis of original research presentations from the academic family medicine meetings of the North American Primary Care Research Group (NAPCRG) (http://www.napcrg.org) and Society of Teachers of Family Medicine (STFM) (http://www.stfm.org) from approximately 25 years ago showed that less than onehalf of all publications were published within 5 years of conference presentation. ${ }^{10}$ Publication productivity in family medicine has increased over the past decade, however. ${ }^{11}$ The objective of this study was to evaluate the proportion of presentations at recent major primary care research conferences that have become published.

\section{METHODS}

\section{Conference Presentations}

Both oral and poster presentations for completed and work-in-progress projects from the 2007 and 2008 NAPCRG annual conferences and peer papers for completed and work-in-progress projects, research forums, and research posters from the 2007 and 2008 STFM annual conferences were evaluated for publication. Educational sessions, workshops, and breakfast roundtable sessions were not included for analysis because the purpose of these sessions is generally not to disseminate research findings. We chose conferences from 2007 and 2008 to allow for up to 4 to 5 years from presentation to publication.

\section{Search}

The search strategy was similar to that used by Elder and Blake ${ }^{10}$ as a way to compare the current results with the last evaluation. The first listed presenter for each presentation was searched on PubMed, the largest clearinghouse of citations on the Internet that includes all journals in the index medicus. The search occurred in April 2012, and was conducted by 2 of the authors (R.E.P., who searched for 2007 STFM, 2007 NAPCRG, and 2008 NAPCRG presentations; and K.E.O., who searched for 2008 STFM presentations). Before review, both authors were in $100 \%$ agreement with their findings after searching the same random sample of 10 presentations. The titles of the presentations were compared with titles of articles found on the PubMed search results. If an article title matched exactly or was reasonably close to the presentation title, then the abstracts for both the article and presentation were compared for content. If these elements were deemed to have been from the same study, then the article was counted as a match. For each publication match found, the following data were collected: the month and year of publication, and the journal in which the report appeared.

\section{Outcome Measures}

The main outcome measure was the proportion of presentations that were published in peer-reviewed journals. Other measures include mean time to publication and the proportions of the type of journal in which the article appeared (family medicine, other general medicine, specialty, or medical education). The time from presentation to publication for each study was calculated as the number of months between conference presentation and publication in a peer-reviewed journal. If a study was published before a conference presentation, then the number of months was recorded for analysis as zero. Statistical analysis was performed using SPSS (Version 19.0, IBM Corporation,).

\section{RESULTS}

Tables 1 through 4 report the proportion of presentations that were published as articles and the mean time to publication. Time to publication ranged from 20 months before presentation to 51 months after presentation, with $8.1 \%(n=37)$ of studies published before their respective conferences.

Publications appeared in 192 different journals. Table 5 shows a breakdown of publication distribution, with the most common journals listed in Table 6.
Table 1. Proportion of Presentations at NAPCRG and STFM Conferences Later Published as Articles in Peer-Reviewed Journals

\begin{tabular}{lccccc}
\hline $\begin{array}{l}\text { Presentation } \\
\text { Characteristic }\end{array}$ & $\begin{array}{c}\text { Presentations } \\
\text { No. }\end{array}$ & $\begin{array}{c}\text { Published } \\
\% \text { (No.) }\end{array}$ & $\begin{array}{c}\boldsymbol{P} \\
\text { Value }\end{array}$ & $\begin{array}{c}\text { Months to } \\
\text { Publication } \\
\text { Mean (SE) }\end{array}$ & $\begin{array}{c}\boldsymbol{P} \\
\text { Value }\end{array}$ \\
\hline Overall & 1,329 & $34.4(457)$ & & $15.4(0.6)$ & \\
At NAPCRG & 1,000 & $36.7(367)$ & .002 & $16.0(0.6)$ & .039 \\
At STFM & 329 & $27.4(90)$ & & $13.1(1.2)$ & \\
In 2007 & 616 & $36.4 \%(224)$ & NS & $15.4(0.8)$ & NS \\
In 2008 & 713 & $32.7 \%(233)$ & & $15.5(0.8)$ & \\
Completed project & 961 & $42.7(410)$ & $<.001$ & $14.6(0.6)$ & $<.001$ \\
Work in progress & 368 & $12.8(47)$ & & $22.7(1.9)$ & \\
Oral presentation & 688 & $42.9(295)$ & $<.001$ & $13.7(0.6)$ & $<.001$ \\
Poster presentation & 641 & $25.3(162)$ & & $18.6(1.0)$ & \\
\hline NAPCRG = North American Primary Care Research Group; NS not significant; STFM = Society of Teachers of Fam- \\
ily Medicine.
\end{tabular}




\section{Table 2. Comparison of Publication Rates of Various Types of Presentations}

\begin{tabular}{lccc}
\hline $\begin{array}{l}\text { Presentation } \\
\text { Type }\end{array}$ & Complete & $\begin{array}{c}\text { Work in } \\
\text { Progress }\end{array}$ & P Value \\
\hline Oral, \% & 47.3 & 11.8 & $<.001$ \\
Poster, \% & 34.9 & 13.1 & $<.001$ \\
$P$ Value & $<.001$ & NS & \\
\hline NS = not significant. & & & \\
\hline
\end{tabular}

Table 3. Comparison of Time to Publication by Type of Presentation

\begin{tabular}{lccc}
\hline $\begin{array}{l}\text { Presentation } \\
\text { Type }\end{array}$ & $\begin{array}{c}\text { Work in } \\
\text { Complete } \\
\text { No. (\%) }\end{array}$ & $\begin{array}{c}\text { Progress } \\
\text { No. (\%) }\end{array}$ & P Value \\
\hline Oral & $13.6(0.6)$ & $16.7(3.8)$ & NS \\
Poster & $16.9(1.1)$ & $24.4(2.2)$ & .002 \\
$P$ Value & .007 & NS & \\
\hline NS = not significant. & & & \\
\hline
\end{tabular}

\section{DISCUSSION}

The finding that two-thirds of research presentations at major academic family medicine meetings appear to not transition to peer-reviewed publications has several implications for the discipline. This rate of publication after presentation at a national meeting may represent major missed opportunities for broad dissemination of findings. Moreover, the publication rate may indirectly measure the quality of presentations at national meetings. Both these implications suggest room for improvement in developing and disseminating scholarship and should be a concern for the discipline.

The room for most improvement appears to be in work-in-progress presentations. These projects may never be completed and would therefore be unlikely to be published. Many work-in-progress presentations are presented by residents and fellows, who may have neither the time nor the resources to complete projects before graduation or who may not wish to complete the project after graduation.

Interest in these studies in the medical community does not appear to be a factor, because many of the studies published appeared in non-family medicine journals. In a previous study, Elder and Blake reported that $56 \%$ of articles were published in family medicine journals. ${ }^{10}$ This rate dropped to less than $37 \%$ in our current study. The publication rate outside the primary discipline journals is similar to other specialties. ${ }^{12}$

There may be some other factors, such as the various reasons attendees may present at a conference: justification for travel funds, improving curriculum vitae, or non-research-oriented professionals trying to
Table 4. Characteristics of Presentations at NAPCRG and STFM Conferences

\begin{tabular}{llll}
\hline Characteristic & NAPCRG & STFM & $\begin{array}{c}P \\
\text { Value }\end{array}$ \\
\hline $\begin{array}{l}\text { Presentations that became } \\
\text { publications, \% }\end{array}$ & & \\
$\quad$ Oral & 45.6 & 35.5 & .019 \\
$\quad$ Poster & 27.7 & 16.8 & .009 \\
$\begin{array}{l}\text { Work in progress } \\
\text { Completed }\end{array}$ & 15.3 & 20.2 & NS \\
$\begin{array}{l}\text { Time to publication, } \\
\text { mean (SE), months }\end{array}$ & 41.7 & 47.7 & NS \\
$\begin{array}{l}\text { Oral } \\
\text { Poster }\end{array}$ & $14.2(0.7)$ & $12.0(1.3)$ & NS \\
Work in progress & $19.0(1.1)$ & $16.1(2.5)$ & NS \\
Completed & $25.1(2.4)$ & $18.9(3.1)$ & NS \\
\hline NAPCRG = North American Primary Care Research Group; NS not significant; \\
STFM = Society of Teachers of Family Medicine.
\end{tabular}

Table 5. Distribution of Articles ( $N=457)$ Published by Journal Type

\begin{tabular}{lc}
\hline Journal Type & Publications, No. (\%) \\
\hline Family medicine & $167(36.5)$ \\
Other general medicine & $155(33.9)$ \\
Specialty & $118(25.8)$ \\
Medical education & $17(3.7)$ \\
\hline
\end{tabular}

\section{Table 6. Most Common Journals in Which Published Articles ( $\mathrm{N}=457$ ) Appeared}

\begin{tabular}{lr}
\hline Journal & No. (\%) \\
\hline Annals of Family Medicine & $50(10.9)$ \\
The Journal of the American Board & $44(9.6)$ \\
$\quad$ of Family Medicine & $31(6.8)$ \\
Family Medicine & $21(4.6)$ \\
Canadian Family Physician & $11(2.4)$ \\
British Journal of General Practice & $10(2.2)$ \\
American Journal of Preventive Medicine & $10(2.2)$ \\
Family Practice & $10(2.2)$ \\
Patient Education and Counseling & $9(2.0)$ \\
BMC Family Practice & $8(1.8)$ \\
Journal of General Internal Medicine &
\end{tabular}

meet a scholarly requirement for their position with no real intention to publish. Also, in comparison with the previous study in family medicine for this topic, ${ }_{1}^{10}$ the publication rate is almost exactly the same (47.3\% vs $47.6 \%$ for oral presentations on completed projects).

STFM and NAPCRG have supported efforts to expand publication opportunities in recent years by supporting journals in the discipline, hosting publication workshops, and promoting research development through the Grant Generating Project and the Council 
of Academic Family Medicine Educational Research Alliance.$^{13}$ Despite these efforts, however, barriers remain, including lack of protected faculty time, lack of mentorship, and lack of specific funding for family medicine research, ${ }^{2,14}$

The lag time between presentation and publication has improved, with more studies now published within 2 years $(78.9 \%)$ than in the previous study of in family medicine $(62 \%)$ published presentations. This outcome could be due to the emergence of a dedicated cohort of family medicine authors who are more active and want to have their studies published. Also, in this era of abundant Internet access, most if not all journals use digital electronic submission for papers, electronic reviewing, and rapid publication of studies in dedicated e-journals or e-publishing ahead of print. With a mean time of about 15 months from presentation to publication, family medicine is comparable to other fields. ${ }^{5,15,16}$

\section{Limitations}

Because this study used only the NAPCRG and STFM conferences to obtain data, other conferences where research is presented, such as the American Academy of Family Physicians Scientific Assembly and Wonca, were not included. Because NAPCRG and STFM have such large conferences, a sufficient sample can be assumed. Only the first presenter was used in searching for publications, so it is possible that some published articles may have been missed if this presenter was not included as one of the authors of a publication. Conversely, some published reports were counted that should never have been accepted to their conferences because they were published before conference submission deadlines, usually about 4 to 8 months before the conference depending on the type of submission. No data about project funding were available for inclusion in this analysis. Finally, other types of scholarly activity are not addressed in this article, such as book chapters and scholarly monographs.

More than one-third of all presentations at STFM and NAPCRG eventually became published. Of note, almost one-half of all oral presentations on completed research became published, which represents no change in the last 20 years. If a presentation does become published, it does so in a timely matter. Furthermore, more than $60 \%$ of publications are not in a family medicine journal, suggesting vast breadth in family medicine research. Family medicine academicians need to refocus efforts on transforming presentations into published articles in peer-reviewed journals for broader dissemination of research findings.
To read or post commentaries in response to this article, see it online at http://www.annfammed.org/content/11/3/258.

Key words: publications; research dissemination; presentations; research report

Submitted May 22, 2012; submitted, revised, October 12, 2012; accepted October 31, 2012.

\section{References}

1. Riordan FA. Do presenters to paediatric meetings get their work published? Arch Dis Child. 2000;83(6):524-526.

2. Sprague S, Bhandari M, Devereaux PJ, et al. Barriers to full-text publication following presentation of abstracts at annual orthopaedic meetings. J Bone Joint Surg Am. 2003;85-A(1):158-163.

3. Schnatz PF, Romegialli A, Abrantes J, Marakovits K, Cunningham D, O'Sullivan DM; North American Menopause Society. The North American Menopause Society: from abstract to publication. Menopause. 2008;15(5):996-1001.

4. Van Royen P, Sandholzer H, Griffiths F, et al. Are presentations of abstracts at EGPRN meetings followed by publication? Eur J Gen Pract. 2010;16(2):100-105.

5. Schulte TL, Huck K, Osada N, et al. Publication rate of abstracts presented at the Annual Congress of the Spine Society of Europe (years 2000-2003). Eur Spine J. 2012; 21(10):2105-2112.

6. Nutting PA. Practice-based research networks: building the infrastructure of primary care research. J Fam Pract. 1996;42(2):199-203.

7. North American Primary Care Research Group Committee on Building Research Capacity; Academic Family Medicine Organizations Research Subcommittee. What does it mean to build research capacity? Fam Med. 2002;34(9):678-684.

8. Steiner JF, Kempe A, Davidson AJ, et al. The case for interdepartmental research in primary care. Acad Med. 2004;79(7):617-622.

9. Peterson KA, Fontaine P, Speedie S. The Electronic Primary Care Research Network (ePCRN): a new era in practice-based research. J Am Board Fam Med. 2006;19(1):93-97.

10. Elder NC, Blake RL Jr. Publication patterns of presentations at the Society of Teachers of Family Medicine and North American Primary Care Research Group annual meetings. Fam Med. 1994;26(6): 352-355.

11. Post RE, Weese TJ, Mainous AG III, Weiss BD. Publication productivity by family medicine faculty: 1999 to 2009. Fam Med. 2012;44(5): 312-317.

12. Scherer RW, Langenberg P, von Elm E. Full publication of results initially presented in abstracts. Cochrane Database Syst Rev. 2007;(2): MR000005.

13. Shokar N, Bergus G, Bazemore A, et al. Calling all scholars to the council of academic family medicine educational research alliance (CERA). Ann Fam Med. 2011;9(4):372-373.

14. Smith MA, Barry HC, Williamson J, Keefe CW, Anderson WA. Factors related to publication success among faculty development fellowship graduates. Fam Med. 2009;41(2):120-125.

15. Amirhamzeh D, Moor MA, Baldwin K, Hosalkar HS. Publication rates of abstracts presented at pediatric orthopaedic society of North America meetings between 2002 and 2006. J Pediatr Orthop. 2012;32(2):e6-e10.

16. Hoag CC, Elterman DS, Macneily AE. Abstracts presented at the American Urological Association Annual Meeting: determinants of subsequent peer reviewed publication. J Urol. 2006;176(6 Pt 1): 2624-2629, discussion 2629. 